\title{
Sediment compaction rates and subsidence in deltaic plains: numerical constraints and stratigraphic influences
}

\author{
T. A. Meckel, ${ }^{1}$ U. S. Ten Brink and S. J. Williams \\ United States Geological Survey, Woods Hole, MA, USA
}

\begin{abstract}
Natural sediment compaction in deltaic plains influences subsidence rates and the evolution of deltaic morphology. Determining compaction rates requires detailed knowledge of subsurface geotechnical properties and depositional history, neither of which is often readily available. To overcome this lack of knowledge, we numerically forward model the incremental sedimentation and compaction of stochastically generated stratigraphies with geotechnical properties typical of modern depositional environments in the Mississippi River delta plain. Using a Monte Carlo approach, the range of probable compaction rates for stratigraphies with compacted thicknesses $<150 \mathrm{~m}$ and accumulation times $<20 \mathrm{kyr}$. varies, but maximum values rarely exceed a few $\mathrm{mm} \mathrm{yr}^{-1}$. The fastest compacting stratigraphies are composed primarily of peat and bar sand, whereas the slowest compacting stratigraphies are composed of prodelta mud and natural levee deposits. These results suggest that compaction rates can significantly influence vertical and lateral stratigraphic trends during deltaic evolution.
\end{abstract}

\section{INTRODUCTION}

Determining compaction rates in modern sedimentary environments is difficult. There are few direct observations and monitoring efforts are expensive and time consuming. Further complications result from our incomplete knowledge of the specific depositional events resulting in the present stratigraphy. Two sedimentary columns with similar compacted thickness and total time of accumulation can have different accumulation histories (sedimentation rates and facies deposited) and are therefore likely to have different present compaction rates. With many borings (as in the Mississippi delta plain), the thickness of a sedimentary unit and the approximate age of accumulation are often available on a regional scale. However, the detailed sedimentation rate and composition of individual layers at any specific location vary locally and are typically not well known. This local variability restricts the lateral distance that calculated site-specific compaction rates can be extrapolated. The limited applicability of site-specific calculations argues for the development of a less specific, but more broadly applicable method to constrain the possible range of compaction rates.

Here, we present a stochastic approach that investigates diverse depositional scenarios (variable layer thicknesses, sedimentation rates and composition) that result in the

Correspondence: T. A. Meckel, United States Geological Survey, Woods Hole, MA, USA. E-mail: tip.meckel@beg.utexas.edu

${ }^{1}$ Present address: Bureau of Economic Geology, John A. and Katherine G. Jackson School of Geosciences, The University of Texas at Austin, TX, USA. same compacted thickness and time of accumulation. This approach allows us to derive the expected bounds of present compaction rates for a stratigraphy in the absence of detailed boring information, to draw some conclusions regarding characteristic behaviour and dependencies of the compaction process in general, and to gain insight into the stratigraphic characteristics that influence the present rates of compaction. To these ends we: (1) present a relatively simple stochastic method for generating synthetic, uncompacted one-dimensional (1D) stratigraphic columns; (2) use Monte Carlo simulations incorporating that method in conjunction with existing compaction routines to constrain the range of anticipated present compaction rates for specific compacted thicknesses and accumulation times and (3) summarize the stratigraphic characteristics of those model stratigraphies which result in relatively fast and slow compaction rates.

We have modelled the shallow compaction that occurs in the upper tens of meters (maximum $150 \mathrm{~m}$ ) over time periods of thousands of years (maximum $20 \mathrm{kyr}$ ), typical of Mississippi Delta deposits during the late Pleistocene and Holocene. We initially focus on an arbitrarily chosen subset of those stratigraphies $(100-110 \mathrm{~m}$ compacted thickness that accumulated in 10-11 kyr). We describe the range of cumulative subsidence and present compaction rates for those stratigraphies, and investigate stratigraphic characteristics that result in fast and slow compaction rates. The present compaction rates for the entire range of modelled stratigraphies $(10-150 \mathrm{~m}$ that accumulated in $1-20 \mathrm{kyr}$ ) are then summarized. We conclude with a comparison of our modelled rates with other observations of 


\section{T. A. Meckel et al.}

subsidence rates from dated peat horizons and suggest how compaction rates may broadly influence vertical and lateral stratigraphic evolution in deltaic plains.

Natural compaction (consolidation, autocompaction) here refers to the reduction in sediment volume (increase in bulk density) as a result of pore collapse (mechanical grain reorganization) and fluid expulsion due to the gravitational load of overlying sediment (overburden). We do not incorporate chemical or biological processes (dissolution, cementation and decay) that may affect compaction. The term 'compaction rate' hereafter refers to the rate of vertical elevation change of the uppermost stratigraphic surface with respect to the base of the compacting column (assumed static) due to compaction integrated over the stratigraphic column.

\section{MODELLED FACIES DATA}

Geotechnical parameters used here to describe the physical properties of consolidating sediments are compressibility (b); Athy, 1930), initial porosity $\left(\Phi_{0}\right)$, bulk density $(\rho)$ and the constants $c_{1}$ and $c_{2}$ relating permeability to porosity (Bryant et al., 1975; Mello et al., 1994).

We are primarily concerned with compaction processes in the coastal plain of southern Louisiana, and have conducted our investigation using data from that environment. For facies comprising the modern Louisiana coastal plain, the most relevant geotechnical data are from Kuecher et al. (1993) and Kuecher (1994). The five modern facies sampled (locations in Kuecher, 1994) are peat, bar sand, natural levee, bay mud and prodelta mud. The geotechnical parameters for these facies that were used in our modelling effort are presented in Table 1 . These values are similar to those presented by Mello et al. (1994; their Table 1), and Kooi \& de Vries (1998; their Table 1). Bulk density, porosity and permeability change in response to loading and are updated throughout the calculations.

\section{NUMERICAL METHODS}

A flow chart illustrating our generalized methodology for creating a synthetic uncompacted stratigraphy and determining the present compaction rate is provided in Fig. 1. Details of each step $(a-f)$ are described below. Specific characteristics of the stochastically generated uncom-

Table 1. Geotechnical parameter values by facies (see Kuecher, 1994)

\begin{tabular}{llllll}
\hline Facies & $c_{1}$ & $c_{2}$ & $\Phi_{0}$ & $b\left(\mathrm{~Pa}^{-1}\right)$ & $\rho\left(\mathrm{kg} \mathrm{m}^{-3}\right)$ \\
\hline Peat & 20.0 & 8.0 & 0.88 & $1.0 \mathrm{E}-06$ & $1.12 \mathrm{E}+03$ \\
Bar sand & 14.0 & 4.0 & 0.57 & $1.0 \mathrm{E}-07$ & $1.88 \mathrm{E}+03$ \\
Natural levee & 20.0 & 6.0 & 0.42 & $5.0 \mathrm{E}-07$ & $1.78 \mathrm{E}+03$ \\
Bay mud & 22.0 & 8.0 & 0.61 & $4.0 \mathrm{E}-06$ & $1.40 \mathrm{E}+03$ \\
Prodelta & 22.0 & 7.0 & 0.78 & $1.0 \mathrm{E}-06$ & $1.22 \mathrm{E}+03$ \\
\hline
\end{tabular}

See text for explanation of symbols.

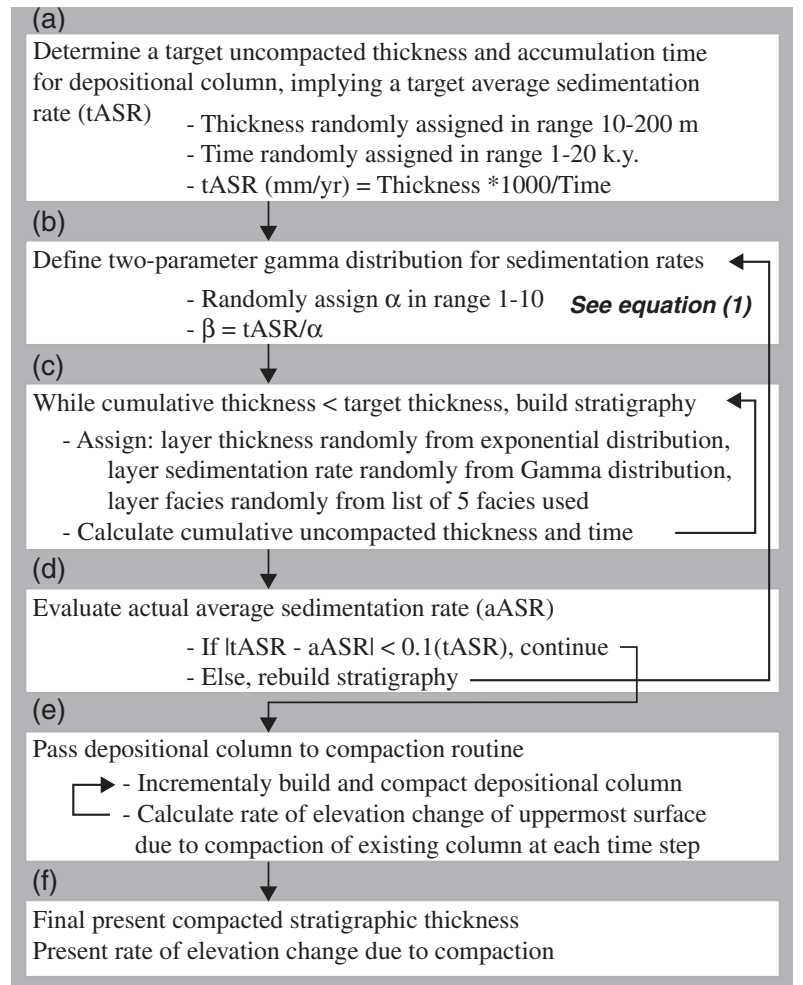

Fig. 1. Flow chart illustrating basic computational procedure for generating an uncompacted depositional column and incrementally building and compacting that column to arrive at a final compacted thickness and compaction rate. Details of each step (a-f) provided in text. Characteristics of the stratigraphies resulting from this method are in Appendix A.

pacted stratigraphies appear in Appendix A. We make no assumptions regarding relationships among facies, depositional layer thickness and sedimentation rate. Input variables that were randomly chosen from predetermined distributions to assemble a stratigraphic model are (1) the depositional thickness for each layer, (2) the sedimentation rate for each layer (implying a certain amount of time for depositing the layer) and (3) the facies assigned to each layer. Our premise is that, by modelling an exhaustive range of possible stratigraphies, any observed stratigraphy composed of similar facies will have a present compaction rate somewhere on our model distributions.

Initially, a target uncompacted thickness and target time of accumulation for a depositional column are chosen (Fig. 1a), implying a target average sedimentation rate (tASR). Then the depositional column is built from the base upward by stacking uncompacted layers of random thickness, deposition rate and facies, and the process is stopped once the target thickness is exceeded. If the actual average sedimentation rate (aASR) of the final uncompacted depositional column is close to tASR, the column is passed to the compaction routine for incremental sedimentation and compaction analysis. If, on the other hand, the final layer assignment is quite thick or the sedimentation rate so low that the time for that layer is quite long, the final uncompacted column will have different tASR and aASR, and the column in rejected. The criterion that we 
apply (|tASR-aASR $\mid<0.1($ tASR $)$ ) in order to retain a column for further analysis allows most columns generated to be retained. This criterion is needed to ensure that the same number of uncompacted stratigraphies (1000) is generated for each ASR and time of accumulation modelled.

Sedimentation rates for each layer were randomly selected from two-parameter $(\alpha$ and $\beta)$ gamma $(\Gamma)$ probability density function $f(x)$ : (See inset of Fig. A1 for example plots)

$f(x)=\frac{1}{\beta^{\alpha} \Gamma(\alpha)} x^{\alpha-1} \times \mathrm{e}^{-x / \beta}$

such that the distribution average $(\alpha \beta)$ is equal to tASR for the chosen target uncompacted thickness and target accumulation time parameters of each stratigraphic model (Fig. 1b). Initially, $\alpha$ is chosen from a uniform random distribution between 1 and 10 , with $\beta$ then equal to tASR $/ \alpha$. $\Gamma$ distributions avoid the undesired outcome of frequently assigning extremely low sedimentation rates when using an exponential probability density function. The values of $\alpha$ and $\beta$ are constant within a single stratigraphic model, but vary between stratigraphies, allowing for different shapes of the $\Gamma$ distribution, even for stratigraphies with the same ASR (tASR). A more constrained method would have a characteristic and well-defined distribution of sedimentation rates for each facies. Data do not exist at this time to allow a distribution for the rates of sedimentation for each facies used in this analysis to be determined. Thus, our more generalized approach is taken.

Individual layer thicknesses were determined by random selection from an exponential probability density function $f(x): f(x)=\lambda e^{-\lambda x}$, where $\lambda^{-1}$ is the distribution average (Fig. 1c). Exponential distributions are common in stochastic models of sedimentation (Dacey, 1979; Wilkinson et al., 2003). Initially, the average bed thickness of the distribution $\left(\lambda^{-1}\right)$ used for all stratigraphic models is defined to be that which is observed in a $64 \mathrm{~m}$ boring in south-central Louisiana (P-1-90, see Roberts et al. (1994) for location and description). Roberts et al. (1994) refer to 13 soil classification units in the $64 \mathrm{~m}$ recovered, providing an average bed thickness of $4.9 \mathrm{~m}$ and $\lambda=0.20$. As this is an average compacted thickness for the current state of compaction for this stratigraphy (the distributions used in our method assign uncompacted thickness to a layer), we use the value of 4.9 only as a starting point. In order to assess the influence of average depositional bed thickness on distributions of present compaction rates, we repeated our method varying only the average bed thickness used in defining the exponential distribution of possible layer thicknesses.

Geotechnical properties for each layer were determined by randomly selecting one of the five model facies for each layer (Table 1). Each facies can appear 0 to $n$ times in the same stratigraphic model, with $n$ representing the (unconstrained) number of layers for that stratigraphy. No cyclicity has been imposed on the models. Although cyclic deposition of a suite of facies is commonly cited in delta systems (Roberts, 1997; Amorosi et al., 2005), no statistics are provided. We note that other 'cyclic' systems such as Pennsylvanian cyclothems and carbonate platforms do not have facies frequencies that are statistically distinguishable from stochastic models (Wilkinson et al., 2003). However, stratigraphies with cyclicity are possible within our methodology, though only by coincidence. Nondepositional events (no thickness in some time interval) are effectively modelled as extremely low sedimentation rates. Erosional episodes resulting in sediment removal are not modelled.

Once a stratigraphy representing an internally consistent (aASR $\sim$ tASR) uncompacted depositional column has been generated (Fig. 1d), it is used as input for incremental sedimentation and compaction modelling (Fig. 1e). For this, we use the calculations of Kooi (1997). The application of these calculations to subsidence problems in the Netherlands has been demonstrated by Kooi et al. (1998), Kooi \& de Vries (1998) and Kooi (2000), so we only briefly explain the method here. Their approach is similar to other 1-D compaction-fluid flow models with no basal flow (Pizzuto \& Schwendt, 1997 and references therein). Important assumptions included in this treatment are: (1) saturated sediments, (2) fluid flow is 1-D in the upward direction and (3) conservation of mass. Kooi \& de Vries (1998) use the fundamental concepts of Darcy flow law, a constitutive relationship between porosity $(\Phi)$ and effective stress $\left(\sigma_{\text {eff }}\right):\left[\Phi=\Phi_{0} \exp \left(-b \sigma_{\text {eff }}\right)\right]$, where $b$ refers to Athy's (1930) usage and $\Phi_{0}$ is the initial porosity from Table 1, and Terzaghi's (1943) principle of effective stress $\left(\sigma_{\mathrm{eff}}=\sigma-p_{\mathrm{fl}}\right)$, where $\sigma$ is total stress and $p_{\mathrm{fl}}$ is fluid pressure. The relationship of permeability $(k)$ with $\Phi$ is modelled as $k=k_{\mathrm{r}} 10^{\left(-c_{1}+\Phi_{c_{2}}\right)}$, where $k_{\mathrm{r}}$ is a reference permeability $\left(1 \mathrm{~m}^{2}\right.$ here), and $c_{1}$ and $c_{2}$ are from Table 1 . For other constants in the calculations (e.g. fluid density, viscosity and compressibility) we follow Kooi \& de Vries (1998).

Each depositional layer is divided into a number of elements that is linearly proportional to its time of accumulation such that the displacement rate of the uppermost surface was calculated every 100 years throughout sedimentation and compaction. At the completion of accumulation of each stratigraphy, the final (present) rate of vertical displacement of the uppermost surface due to integrated compaction throughout the column was determined, as well as the final (present) compacted thickness (Fig. 1f).

In order to consider a wide range of stratigraphic thicknesses and accumulation times, the parameter space of uncompacted thickness $(10-200 \mathrm{~m})$ and accumulation time $(1-20 \mathrm{kyr})$ was divided into 361 bins $(19 \times 19)$, each spanning $10 \mathrm{~m}$ in thickness and $1 \mathrm{kyr}$ in duration. Each bin was populated with 1000 stochastically generated uncompacted stratigraphies (361000 total stratigraphies). This ensured that each bin in the 10-150 $\mathrm{m}$ thickness range of interest contained $>1000$ compacted stratigraphies. Stratigraphies with uncompacted depositional thickness $>200 \mathrm{~m}$ were not modelled. There may be some stratigra- 
phies that we did not model with uncompacted depositional thickness $>200 \mathrm{~m}$ that could compact to our range of interest $(10-150 \mathrm{~m})$, but they are rare and thus do not contribute substantially to our statistical compaction rate distributions.

\section{RESULTS}

\section{Present compaction rates and subsidence magnitudes}

Here, we present the characteristic compaction behaviour of a subset of the stratigraphies we modelled: those stratigraphies with final compacted thicknesses between 100 and $110 \mathrm{~m}$ and with accumulation times between 10 and $11 \mathrm{kyr}(N=1087)$. The variability of present compaction rates that results from a wider range of present thicknesses $(10-200 \mathrm{~m})$ and accumulation times $(1-20 \mathrm{kyr})$ are presented farther below.

The modelled present compaction rates of this subset vary over three orders of magnitude $\left(10^{-1}-10^{2} \mathrm{~mm} \mathrm{yr}^{-1}\right.$; Fig. 2), but the central $80 \%$ of the results are between 0.69 and $2.2 \mathrm{~mm} \mathrm{yr}^{-1}$ (i.e. fairly low). We hereafter use $P_{10}$ to refer to the $10 \%$ rate $\left(0.69 \mathrm{~mm} \mathrm{yr}^{-1}\right)$ from the cumulative distribution function (CDF) and $P_{90}$ for the $90 \%$ rate $\left(2.2 \mathrm{~mm} \mathrm{yr}^{-1}\right)$.

The cumulative magnitudes of compaction (subsidence) of the subset (Fig. $3 \mathrm{a}$ and $\mathrm{b}$ ) also vary over two orders of magnitude $\left(<10^{0}-10^{2} \mathrm{~m}\right.$; Fig. 3c). However, $90 \%$ of modelled total subsidence magnitudes are $<20 \mathrm{~m}$, and $80 \%$ are $<7 \mathrm{~m}$. The present compaction rate does not correlate strongly with the magnitude of subsidence for the same stratigraphy (Fig. 3d; correlation coefficient $=0.28$ ). Present compaction rates cannot be inferred from current magnitudes of subsidence. Current magnitudes of subsidence cannot be inferred from present compaction rates.

\section{Stratigraphic influences on present compaction rates}

Here, we investigate the characteristics of the subset of stratigraphies with relatively high and low present compaction rates ( $>P_{90}$ and $<P_{10}$, respectively; Fig. 2 ). By analysing a large number of stratigraphies with similar compacted thicknesses and accumulation time $(N=1087)$, we have allowed stratigraphies to naturally sort themselves into subsets with similar present compaction rates (natural sorting). This is an advantage of Monte Carlo simulations for informal sensitivity analyses.

\section{Layer thickness}

We did not impose any order or cyclicity in layer thickness in our stochastic method for generating uncompacted depositional columns, so model stratigraphies will rarely show such trends. Thus, our methodology does not allow us to make any statements regarding relationships between trends in uncompacted layer thickness and present compaction rate.

However, it is possible that the thickness of the most recently assigned layer correlates with the present compaction rate by dominating the signal. That is, assigning thicker units (which have a constant facies and sedimentation rate) towards the present may allow individual layers

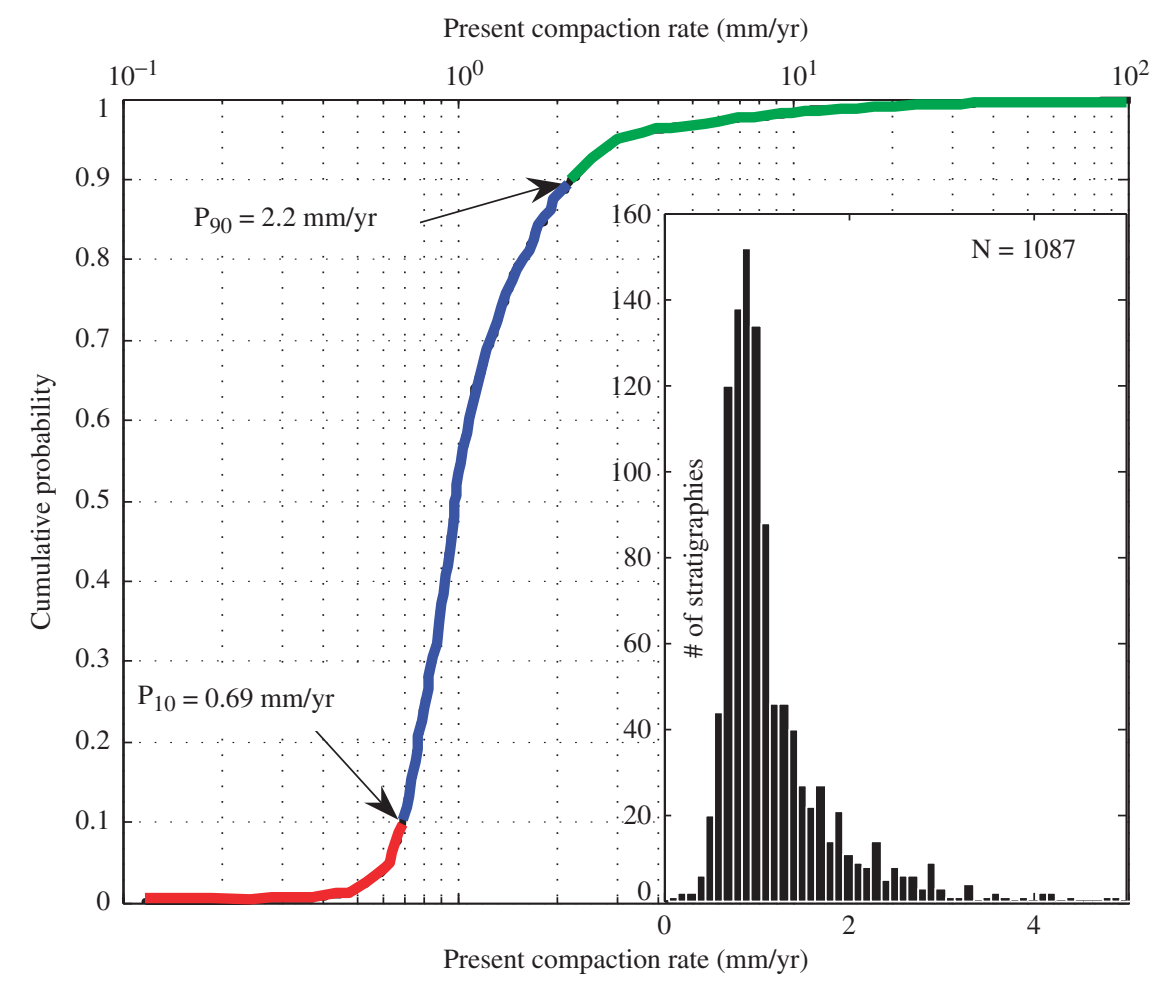

Fig. 2. Cumulative probability distribution function (CDF) for present compaction rates for stratigraphies with compacted thickness $100-110 \mathrm{~m}$ and accumulation time 10-11 kyr The rate corresponding to the $n$th percentile is the rate below which $n \%$ of the modelled values occur. The central $80 \%$ of modelled values occur between the 10th and 90th percentiles $\left(P_{10}, P_{90}\right.$ labelled). Colours correspond to subsets shown in Figs 3 a and 5. Inset frequency distribution (histogram) shows same rates from which CDF was constructed. 


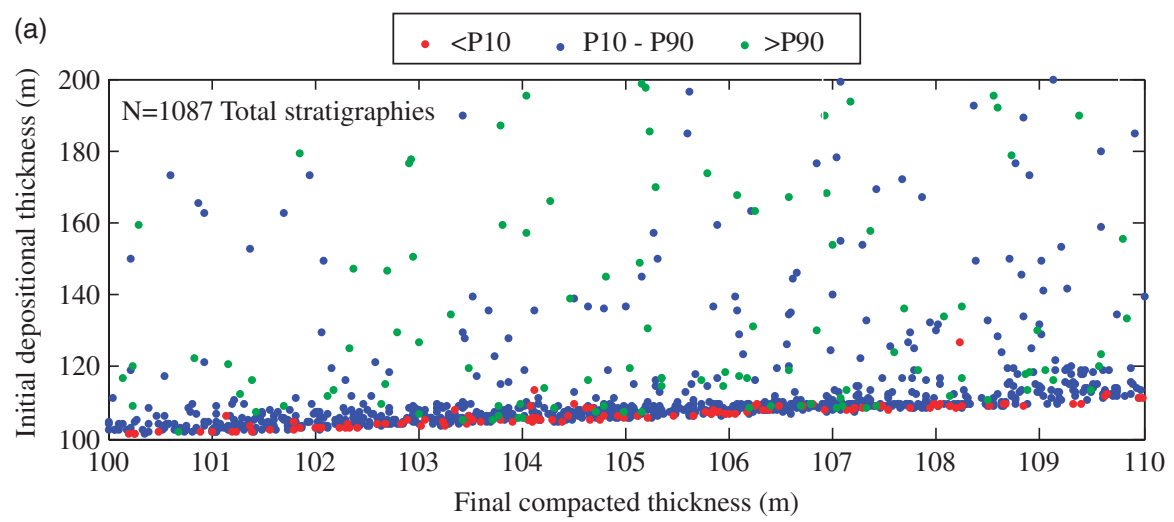

Fig. 3. Data for cumulative compaction (subsidence). (a) Initial depositional thickness vs. final compacted thickness. Different colours represent different subsets of the cumulative probability distribution function (CDF) in Fig. 2. (b) Frequency distribution of subsidence magnitudes used to create CDF in (c). (d) Present compaction rates do not correlate strongly with the magnitude of subsidence (correlation coefficient $=0.28$ ).
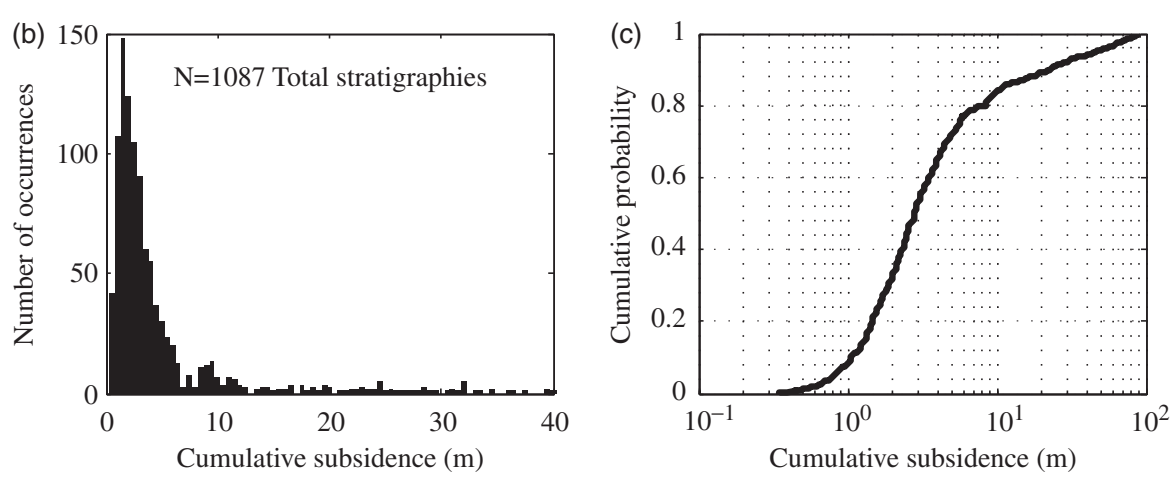

(d)

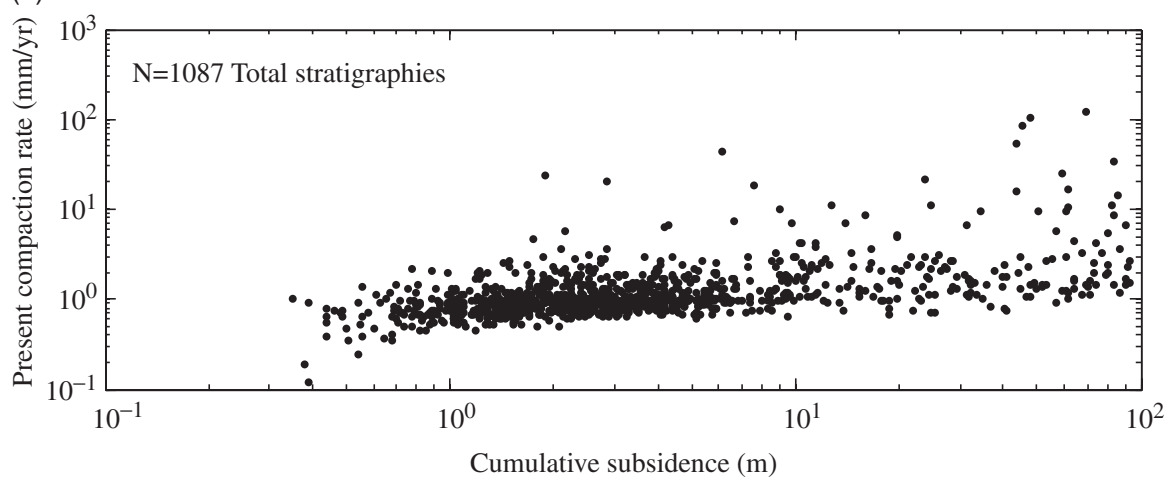

to potentially exert a dominant influence (fast or slow) on present compaction rate. Having rapidly changing thickness (and consequently facies and sedimentation rate) towards the present may prevent any single facies from dominating the present compaction rate. We compared the most recent layer thickness assignments with present compaction rates. No relationship was identified, indicating that present compaction rates cannot be attributed to recently assigned layer thickness in the uncompacted depositional column.

To further investigate the influence of layer thickness, we repeated the procedure used to generate the modelled CDF in Fig. 2 changing only one parameter: the average layer thickness used to define the exponential distribution from which uncompacted layer thicknesses were chosen. We repeated the process twice using values for average layer thickness of 2.5 and $7.5 \mathrm{~m}$. These values represent approximately 0.5 , and 1.5 times that used to generate Fig. 2
$(4.9 \mathrm{~m})$. The CDFs from these results are presented in Fig. 4 , and indicate that present compaction rates are not very sensitive to changes in average uncompacted layer thickness used to construct the stratigraphies $\left(P_{90}\right.$ rates vary by $<0.5 \mathrm{~mm} \mathrm{yr}^{-1}$ ).

\section{Sedimentation rates}

Layer sedimentation rates were chosen randomly, and are independent of the position in the depositional column. Thus, we do not expect trends in recent sedimentation rates to exist other than by coincidence. However, through natural sorting, the fastest compacting stratigraphies may have similar patterns of sedimentation rates (e.g. rapid recent sedimentation). For the stratigraphies of interest, the most recently assigned layer sedimentation rate does not correlate strongly with present compaction rate (correlation coefficient $=0.10$ ). 


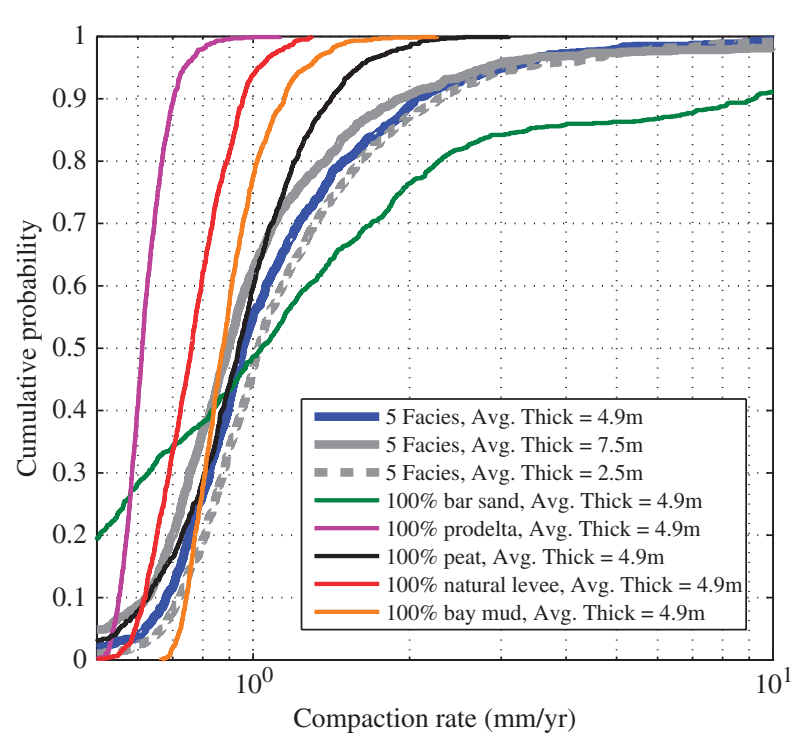

Fig. 4. Cumulative probability distribution functions (CDF) for a variety of model parameters indicated in the key. Each curve represents $>1000$ stratigraphies with compacted thickness between 100 and $110 \mathrm{~m}$ that accumulated in 10-11 kyr Varying average bed thickness used to define the exponential uncompacted bed thickness distribution by $\pm 50 \%$ does not have a dramatic influence on present compaction rates. The range of present compaction rates for stratigraphies consisting of $100 \%$ of each of the five-model facies used from the Louisiana coastal plain are shown for reference.

\section{Facies proportions}

Stratigraphic heterogeneity influences compaction rates. It seems intuitive that the fastest compacting stratigraphy might be composed of $100 \%$ peat (the most compactable material), but our data do not confirm this. Figure 4 shows that the range of compaction rates for entirely homogenous stratigraphies is generally slower than the heterogeneous stratigraphies, except for stratigraphies composed of $100 \%$ bar sand, which have the widest range and most extreme compaction rates. The low density of peat does not allow columns of $100 \%$ peat to compact as fast as those that include some proportion of other facies.

For stratigraphies with present compaction rates $>P_{90}$ and $<P_{10}$ we determined the proportion of each facies in the uncompacted (depositional) column and compared those values with present compaction rates (Fig. 5). Some qualitative observations are notable: high proportions of deposited peat favour current compaction rates $>P_{10}$; high proportions of natural levee favour present compaction rates $<P_{90}$; high proportions of bay mud favour a current rate in the $P_{10}-P_{90}$ range. However, correlation coefficients are generally quite low for an individual facies, with peat being the highest at 0.25 . Some stratigraphies with low proportions of peat have present compaction rates $>P_{90}$, and the converse is also true (Fig. 5, upper left). Furthermore, these results are not easily applied; given observations of an existing stratigraphy of interest, it is unlikely that one would know what the facies proportion of the uncompacted thickness would have been.
More complex is the relationship among present compaction rates, the time or depth interval during which more compactable facies were deposited, and the subsequent loading history. For example, the influence that compactable facies deposited thousands of years ago have on present compaction rates may (or may not) be negligible, depending on their burial history. To investigate this, we computed the running averages of the proportion of each facies throughout deposition, both with respect to cumulative stratigraphic time and uncompacted depositional thickness.

For the running averages, the time window width was 100 years, or $20 \%$ of the average deposition time per layer (given average layer thickness is $\sim 5 \mathrm{~m}$ and ASRs are $\sim 10 \mathrm{~mm} \mathrm{yr}^{-1}$ ). For the thickness window width, the window size is $5 \mathrm{~m}$ (average layer thickness). Other window widths were tried, but the parameters above provided the most efficient trade off between resolution and computation time. All window and step combinations showed similar gross patterns. Owing to extremely long computational times, the $P_{10}-P_{90}$ stratigraphies $(N=869)$ were not analysed in this manner.

Figure 6 suggests that the proportion of peat in the uncompacted depositional column influences the present compaction rate, which is expected (Bloom, 1964; Berry \& Poskitt, 1972; Kuecher et al., 1993; Roberts et al., 1994; Pizzuto \& Schwendt, 1997; Long et al., 2006). The slowest compacting stratigraphies (left side of Fig. 6) have low proportions of peat throughout, decreasing towards the present, and high proportions of prodelta mud. The fastest compacting stratigraphies (right side of Fig. 6) have peat as the highest proportion of window thickness, followed by bar sand, throughout the total accumulation time and uncompacted stratigraphic thickness.

The proportion of peat that accumulated in an uncompacted stratigraphic section is useful for estimating the present compaction rate (Fig. 6), but it is clearly not diagnostic given the weak correlation noted previously for the total proportion of each individual facies with present compaction rate (Fig. 5; upper left).

\section{Facies order}

High compaction rates are likely to result from loading a compactable material with a high-density material with high porosity and permeability. A natural example of such a scenario is the loading of peat occurring at relatively shallow depth intervals (before it is mostly compacted; the determination of that depth is the subject of ongoing research) with bar sand. Indeed, the fastest five compacting stratigraphies (compaction rates $>P_{99}$ on Fig. 2) show just such a behaviour for their most recent history. This suggests that the repeated sedimentation of peat and sand would tend to generate high compaction rates. That concept is validated in the model data by the high peat and sand content throughout the stratigraphies with present compaction rates $>P_{90}$ (Fig. 6; right side). There is no correlation between the most recently assigned facies and the present compaction rate. 


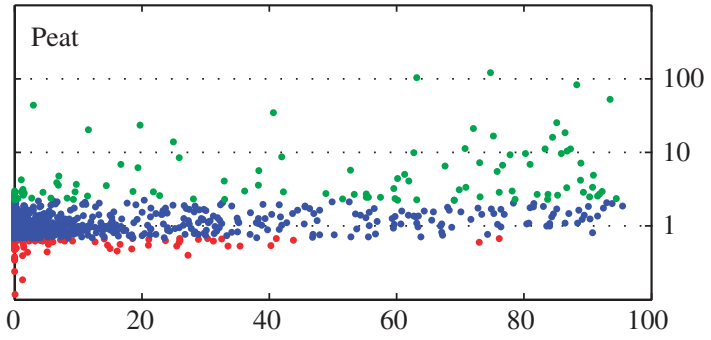

Proportion $(\%)$ of facies in each uncompacted stratigraphy

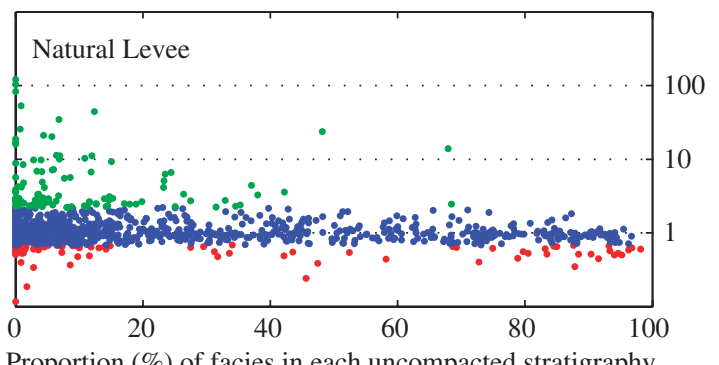

Proportion $(\%)$ of facies in each uncompacted stratigraphy
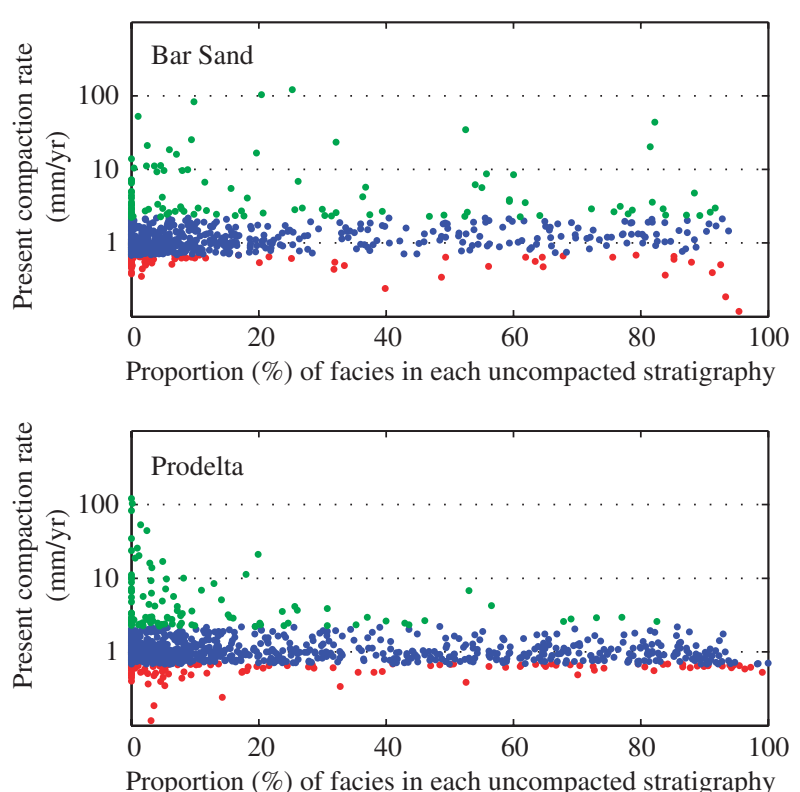

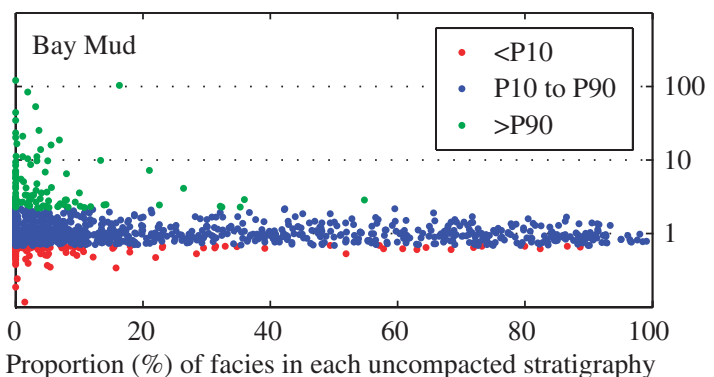

Fig. 5. Different proportions of each of the five-model facies in the uncompacted stratigraphies compared with the present compaction rate for that stratigraphy. The same 1087 stratigraphies (see Fig. 2; each represented by a single point) are represented in each plot. Different coloured points represent the stratigraphies comprising the three different subsets of the cumulative probability distribution functions in Fig. 2. There is a very inconsistent correlation between the proportion of a single facies in the uncompacted column and the present compaction rate.

Faster compaction rates are favoured by high proportions of compactable facies (i.e. peat) that are loaded with high density, permeable materials such as bar sand. Slower compaction rates are favoured by low proportions of compactable material deposited combined with high proportions of facies that make good hydrologic seals (in our case, prodelta mud).

\section{Average net accumulation rates (NARs)}

The average NAR is the compacted thickness divided by the time of accumulation. Here, we consider distributions of present compaction rates for a range of NAR and times of accumulation, of which the stratigraphies previously focused on are only a subset. The model data for stratigraphies that compacted to $10-150 \mathrm{~m}$ and that accumulated in 1-20 kyr indicate that higher NAR rates shift CDFs of present compaction rates to higher values (Fig. 7). We arbitrarily consider $P_{90}$ and $P_{10}$ rates to be the maximum and minimum (respectively) probable compaction rate for each CDF in Fig. 7. For each CDF in Fig. 7, $P_{90}$ and $P_{10}$ rates are plotted with their corresponding thickness and time of accumulation in Fig. $8 \mathrm{a}$ and b. For a given time of accumula- tion, $P_{90}$ values increase with increased thickness (Fig. $8 \mathrm{a}$ ). For a given thickness, $P_{90}$ values decrease with time of accumulation. $P_{10}$ rates show similar behaviour to $P_{90}$ rates (Fig. 8b). The reader can use Fig. 8 to estimate the $P_{10}-P_{90}$ range of probable compaction rates for any combination of compacted thickness and time of accumulation that we modelled.

\section{DISCUSSION}

To summarize, the distributions of present compaction rates of all our modelled stratigraphies are strongly influenced by the average NAR. Distributions of modelled compaction rates shift towards higher values with increased NAR, as expected. Focusing on a specific group of stratigraphies of interest (e.g. 100-110 $\mathrm{m}$ in $10-11 \mathrm{kyr}$ ), the present compaction rate is further influenced by the proportion and combinations of specific facies in the uncompacted depositional column (notably peat, bar sand, and prodelta mud). Position on extreme portions of a CDF (e.g. $>P_{90}$ or $<P_{10}$ ) can be related to general lithologic composition. The conclusions of the stratigraphic 


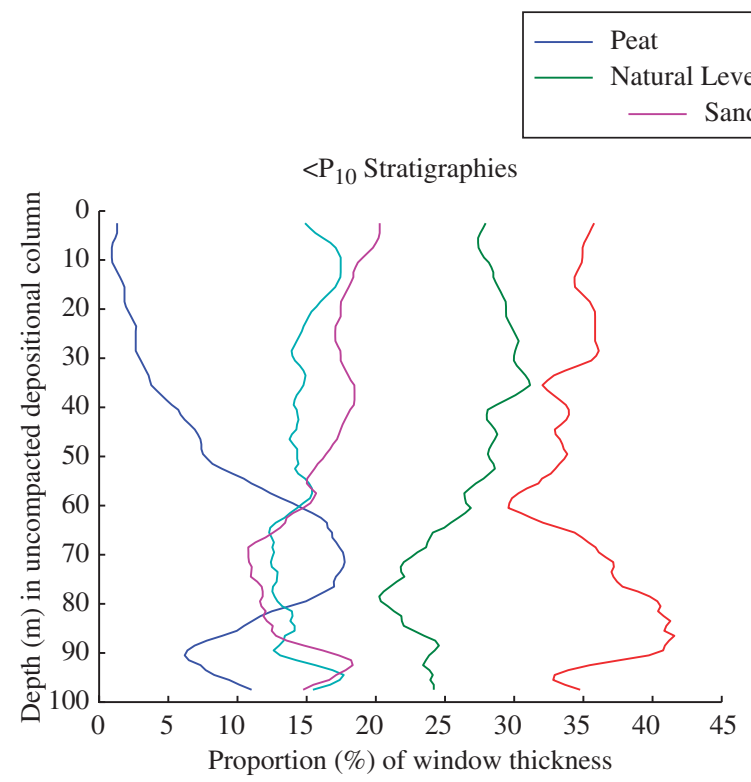

$\begin{array}{ll}\longrightarrow & \text { ProDelta } \\ \text { Bay Mud }\end{array}$
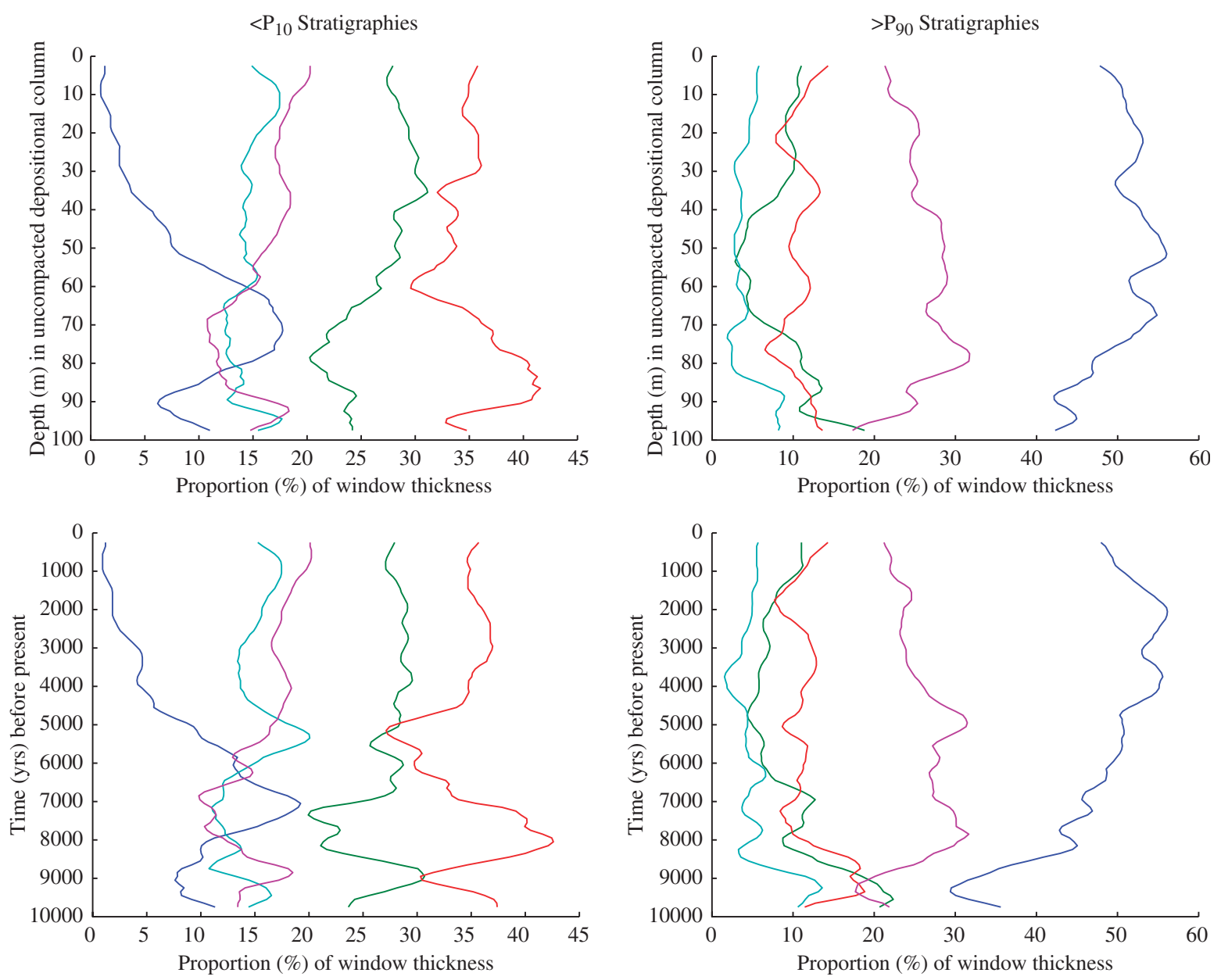

Fig. 6. Running averages of the proportion (\%) the five different model facies throughout deposition. Each curve is an average of the fastest or slowest compacting stratigraphies $(N=109)$. Left: stratigraphies with present compaction rates $<P_{10}$. Right: stratigraphies with present compaction rates $>P_{90}$. Top row: percent of each facies within the moving average window (see text) with respect to uncompacted depositional thickness. Second row: same as top row, but the vertical axis represents time before present. Slow compacting stratigraphies have low proportions of peat and high proportions of prodelta mud throughout. The fastest compacting stratigraphies are composed predominantly of peat with lesser amounts of bar sand throughout.

influences for the subset of stratigraphies investigated likely hold for other compacted thicknesses and times of accumulation, but have not been verified.
Present compaction rates should not be speculated upon knowing only the facies of surficial deposits. Modelling data indicate that low density, highly compactable

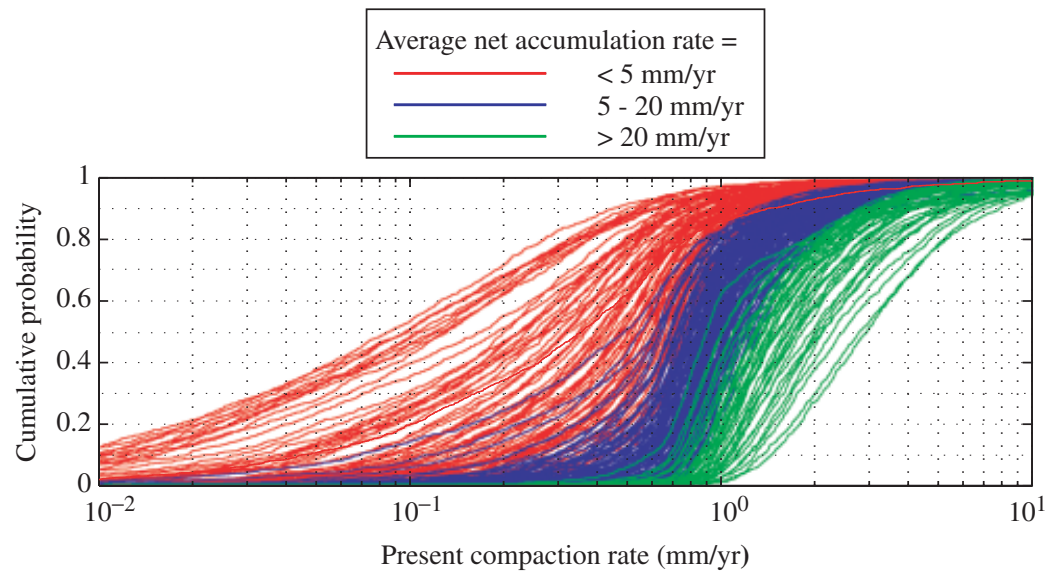

Fig. 7. Cumulative probability distribution functions (CDFs) of present compaction rates for a wide range of compacted thicknesses and times of accumulation. Different colours represent stratigraphies with different average net accumulation rates [net accumulation rates (NAR) in Fig. 8]. 


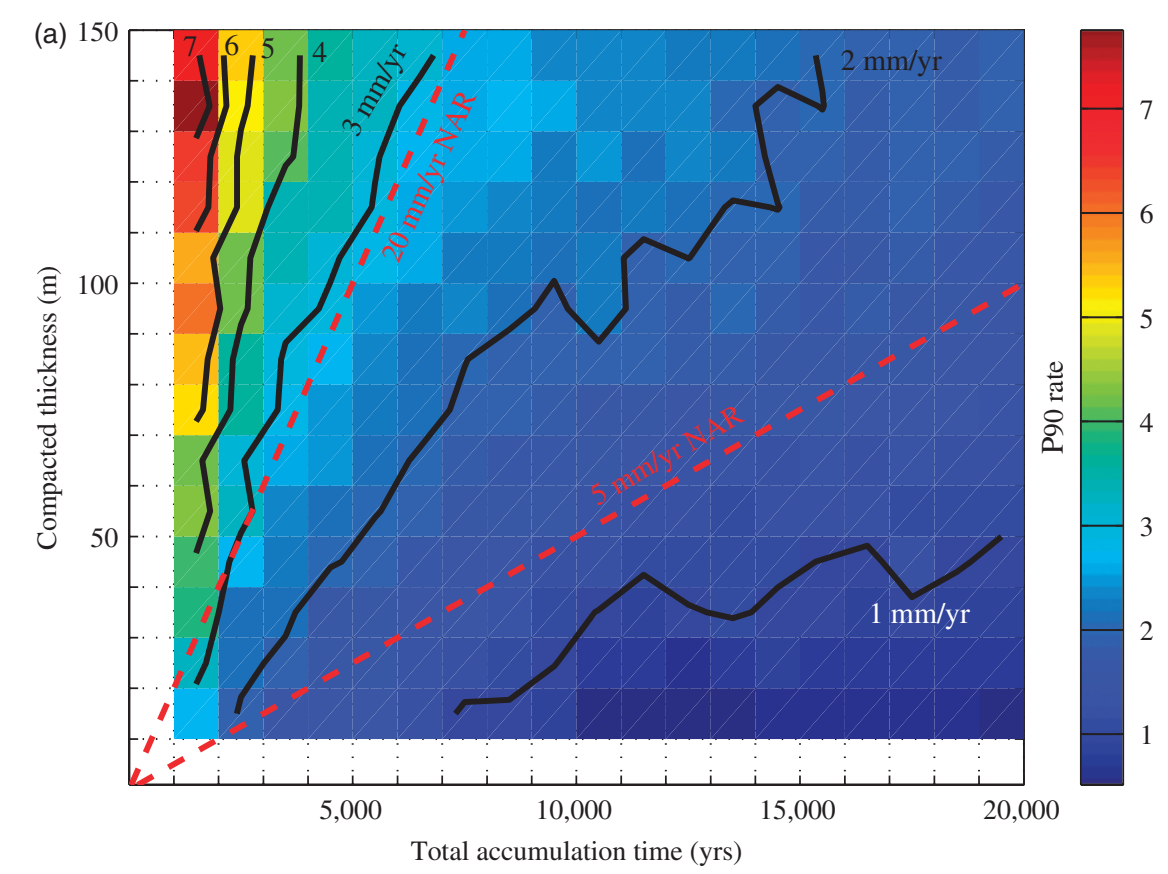

Fig. 8. $P_{90}\left(\right.$ a) and $P_{10}($ b) present compaction rates from the cumulative probability distribution functions (CDFs) in Fig. 7 plotted with their corresponding thickness and accumulation time. This figure can be used to determine the $P_{10^{-}}$ $P_{90}$ range of probable present compaction rates for any shallow stratigraphy with known compacted thickness and time of accumulation. Dashed red lines represent constant net accumulation rates (NAR) of 5 and $20 \mathrm{~mm} \mathrm{yr}^{-1}$. Black curves contour constant compaction rates (labelled).

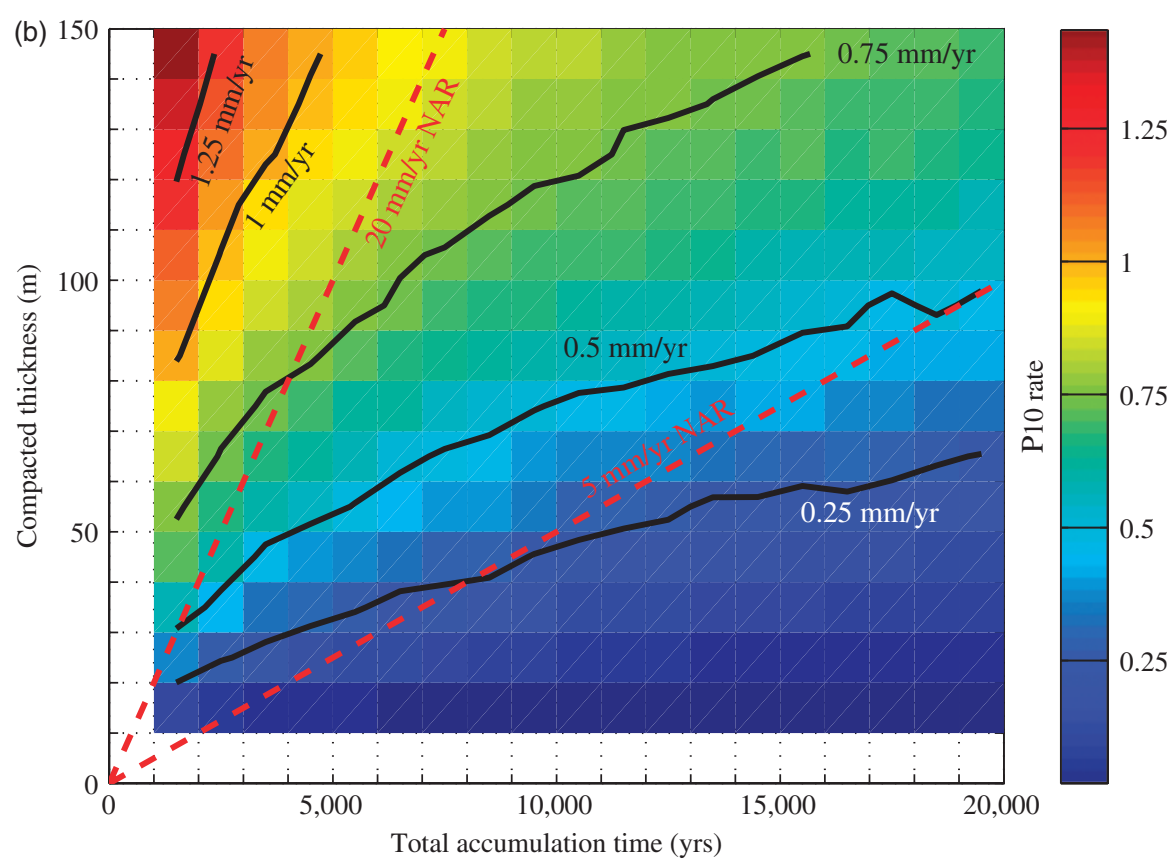

deposits such as peat at the surface can be associated with a wide range of compaction rates, which reflect the deeper geology. High density, permeable sediments such as sand, at the surface (typically considered relatively stable) can be associated with high compaction rates, especially if they overlie thick peat deposits.

\section{Number of realizations}

Some concern was devoted to verifying that the number of model realizations ( $>1000$ per stratigraphy) is sufficient to characterize the full range of possible present compaction rates. The CDF distributions do not vary significantly when the number of realizations increases 10 -fold. The improvement to the CDF shape does not justify the addi- tional computational expense. Our modelled samples adequately represent the full range of variability in the model procedure, and the present compaction rate for any model stratigraphy would fall somewhere on our CDF for the corresponding present thickness and time of accumulation.

\section{Relaxing model constraints}

Present compaction rates vary minimally but consistently as a result of changes in the average bed thickness used to construct uncompacted stratigraphies (Fig. 4). Using a smaller average thickness results in negligibly higher present compaction rates; a larger average thickness results in 


\section{T. A. Meckel et al.}

negligibly smaller present compaction rates. The variability is $<0.5 \mathrm{~mm} \mathrm{yr}^{-1}$ for $P_{90}$ values.

We recognize that facies are not likely to have single parameter values, as in Table 1 . Ideally, rather than having single values for each parameter for each facies, each facies would have a known (observed) distribution of values for each parameter from which values would be selected in a Monte Carlo approach. Rather than using a range of values that is currently less justifiable (not yet observed) for facies of the Mississippi Delta plain, we chose to use actual values measured from the field samples. While this is a limitation of the model, it does not invalidate the results. Using a range of parameter values could change the shape of distributions in Figs 2 and 4. However, solutions would still likely fall in the range illustrated in Fig. 7, although that cannot be confirmed without generating a completely new set of model results.

Were facies to have distributions of parameter values, distributions may overlap. With overlapping distributions, the term 'facies' as used in this modelling would cease to have discernible meaning. As one goal of this research was to assess the influence of different facies on subsidence and compaction rates, it was necessary to have distinct and limited geotechnical properties for each facies.

\section{Modelled compaction rates and observed subsidence rates}

Our efforts to model compaction rates stemmed from the lack of available direct observations. However, we can compare our modelled rates to subsidence rates from other types of observations over similar time scales (i.e. thou-

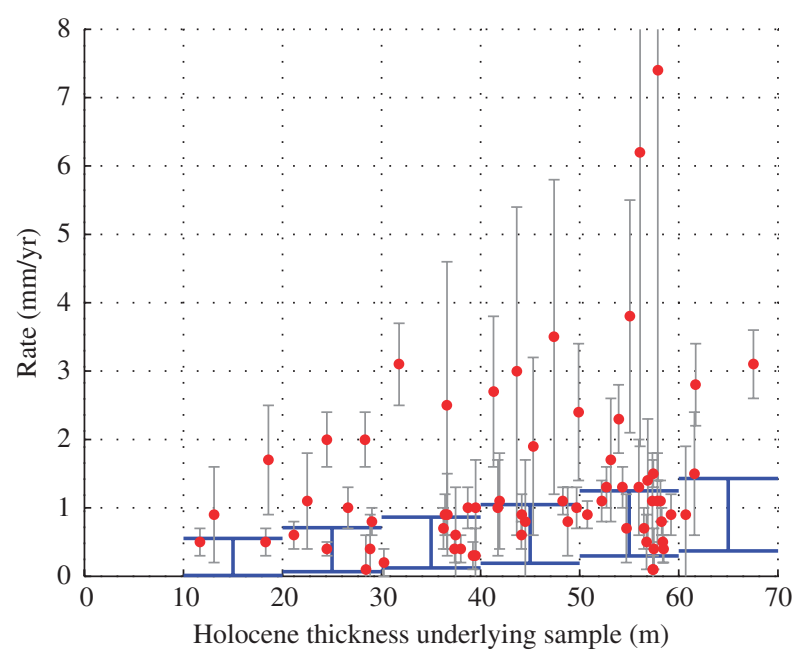

Fig. 9. Comparison of subsidence rates determined from $68{ }^{14} \mathrm{C}$ samples (red points) with the expected $P_{10}-P_{90}$ range of compaction rates (blue lines) for the thickness of Holocene sediments underlying the ${ }^{14} \mathrm{C}$ samples. Approximately half of the ${ }^{14} \mathrm{C}$ rates are within the expected modelled range of rates for shallow compaction. Differences between ${ }^{14} \mathrm{C}$ rates and modelled compaction distributions indicate processes in addition to Holocene compaction are likely to contribute to subsidence for at least half of the sites (Meckel et al., 2006). sands of years). Figure 9 compares our predicted compaction rates with subsidence rates determined from buried peat samples. Kulp (2000) provides subsidence rates for radiometrically dated $\left({ }^{14} \mathrm{C}\right)$ peat horizons in southern Louisiana corrected for calendar age and paleo-sea level changes.

We chose a subset of samples with ages $<1 \mathrm{kyr}$ and burial depths $<3 \mathrm{~m}(N=68$; locations mapped in Meckel et al., 2006) which minimize potential correction errors, presumably reflect only recent subsidence, and are the most appropriate for comparing with our model results because the amount of overburden has been minimized. Using the subsample stratigraphic thickness, an estimate of the total accumulation time, and Fig. 8, the radiometric subsidence rate can be compared with expected model compaction rates (Fig. 9; see Meckel et al., 2006 for details).

Subsidence rates determined from radiometrically dated peat samples in the Louisiana coastal plain are generally within the expected range $\left(P_{10}-P_{90}\right)$ of modelled compaction rates for the stratigraphy underlying the sample. This is reasonable because both methods are essentially measuring subsidence at very long time scales (sediment accumulation and compaction over thousands of years). The fact that some radiometric subsidence rates are higher than the expected distribution of modelled compaction rates suggests that processes other than shallow compaction (Penland \& Ramsey, 1990; Morton et al., 2005; Dokka, 2006) likely contribute to subsidence at those locations (Meckel et al., 2006). Regionally and over geologic time scales, compaction seems to reasonably explain subsidence rates from many radiometric data, and compaction is therefore likely to influence lateral and vertical stratigraphic patterns.

\section{Compaction and stratigraphic evolution}

We have discussed how lithologic composition (facies) influences compaction rates. It is tempting to speculate on how our modelled compaction rates might, in turn, influence the geologic evolution of deltas (i.e. delta progradation, crevasse splay events, delta lobe switching, stratigraphic trends) such as the Mississippi River delta (Coleman et al., 1998). We will assume that the stratigraphic characteristics of the fastest and slowest compacting stratigraphies identified for the small subset of stratigraphies also apply to the wider range of thicknesses and times of accumulation modelled.

Stratigraphies composed of high proportions of prodelta mud (e.g. Fig. 4, 100\% prodelta mud curve) or a combination of prodelta mud and natural levee (e.g. Fig. 6, left side) result in some of the lowest modelled compaction rates. These stratigraphies should facilitate delta lobe progradation, as sedimentation rates can easily exceed the expected compaction rates. This concept is supported by the observation of the dramatic seaward protrusion of the modern 'birdfoot' delta of the Mississippi River. Our results predict slow compaction rates for stratigraphies typical of the natural levees in the lower reaches of the 
Mississippi River (where natural levee deposits overly prodelta muds; as in Fig. 6, left side). Slow local compaction rates in these environments likely inhibited the river from avulsing (before artificial levee construction) the noticeably short distance $(<3 \mathrm{~km})$ to the coast at Breton Sound, $\mathrm{LA}$, or to the west at the Barataria Bay region. The low tidal range, dominance of river inputs and lack of accommodation space (including slow compaction rates) favour progradation (Galloway \& Hobday, 1996).

Landward of extending delta distributaries such as the Mississippi's birdfoot, deposition evolves as bays fill with mud, organic marshes accrete (e.g. peat in our models), and local distributaries deposit bar sands and natural levees. The high predicted compaction rates of stratigraphies composed of peat and bar sand (Fig. 6, right side), as might typically be encountered at the margin of a distributary meander belt (Rajchl \& Uličný, 2005), may encourage crevasse splay processes. On a broader scale, as entire inter-distributary regions accumulate higher proportions of peat, their regional evolution towards generally higher predicted compaction rates may eventually encourage river avulsion due to resulting gradient advantages, and the formation of a new delta lobe. Prior avulsion studies have focused on substrate erodibility and high aggradation rates (Törnqvist, 1994; Aslan et al., 2005). We provide predicted rates of compaction in these various environments for consideration in models of avulsion.

Overall, subtle variability in compaction rates of heterogeneous deposits (which are expected to be slightly faster, on average, than homogeneous deposits; Fig. 4) may influence the regional evolution of deltaic morphology and stratigraphy over geologic timescales. Our compaction results are consistent with the depositional evolution of deltas that has been described for decades (Fisk, 1944; Roberts, 1997). We suggest that the generalized vertical stratigraphic trends of a depositional lobe at the $100-\mathrm{m}$ scale may in fact betray underlying stochastic depositional processes at the (sub)meter scale, and their influence on compaction rates. Stratigraphic composition influences compaction rates, and compaction rates may influence long-term stratigraphic evolution. We have demonstrated the former, but can only speculate on the latter until it can be more fully explored using integrated and dynamic 3D models of sedimentation and compaction. Yet, our results begin to reconcile the heterogeneity that is actually observed at small scales vertically and laterally in deltaic successions with the larger-scale upward stratigraphic trends that have been so successfully applied towards understanding deltaic evolution, were geotechnical properties drastically different than what is observed in modern environments (e.g. extremely compactable prodelta deposits, or incompressible peat accumulations), an entirely different 'typical' delta-lobe stratigraphy may result. Such concepts may be useful for understanding variability in stratigraphic evolution of deltas in different latitudes (e.g. equatorial vs. arctic), as the geotechnical properties of the various facies may differ.

\section{SUMMARY}

We use stochastic forward models of incremental sedimentation and compaction to constrain present compaction rates for stratigraphies with specific present compacted thickness and time of accumulation, and to identify stratigraphic characteristics that influence compaction rates. The rates and subsidence magnitudes presented here are the most comprehensive estimates to date of the contribution of shallow compaction in deltaic environments.

Compaction is a complex nonlinear process; the instantaneous result is a combination of many variables, encompassing prior and present depositional events. Modelled compaction rates for stratigraphies characteristic of the Holocene of the Mississippi River delta are generally less than a few $\mathrm{mm} \mathrm{yr}^{-1}$. Stratigraphic heterogeneity increases compaction rates. Modelled compaction rates do not correlate consistently with cumulative subsidence, recent sedimentation rates, or the thickness and facies of the most recently deposited layer.

Of the model stratigraphies that we analysed in detail, the fastest compacting stratigraphies have high proportions of peat and bar sand throughout, whereas the slowest compacting stratigraphies have low proportions of peat and high proportions of prodelta mud, followed in abundance by natural levee deposits. These proportions refer to the uncompacted depositional column, before sedimentation and compaction.

Modelled compaction rates are similar to many longterm radiometric subsidence rates in the Louisiana delta plain, suggesting that compaction can account for much of (but not all of) the rate of accommodation space created during the Holocene. Thus, compaction rates may be a dominant influence of vertical and lateral stratigraphic trends during Holocene deltaic evolution.

\section{ACKNOWLEDGEMENTS}

This research was conducted during a USGS Mendenhall Research Fellowship held by the lead author. We are grateful to H. Kooi for generously providing compaction routines. This manuscript benefited from geostatistical discussions with A. Solow, B. Wilkinson, L. Lake and J. Jensen. Helpful reviews before submission were provided by W. Barnhardt (USGS) and B. Dugan (Rice University).

\section{APPENDIX A}

Here, we provide detailed information regarding the characteristics of the modelled stratigraphies that resulted from our methodology to construct uncompacted stratigraphies. These data are for stratigraphies that have compacted thicknesses of $100-110 \mathrm{~m}$ and that accumulated in $10-11 \operatorname{kyr}(N=1087)$.

The $\alpha \beta$ pairs that define the shapes of $\Gamma$ distributions used to randomly assign layer sedimentation rates for the 


\section{T. A. Meckel et al.}

modelled stratigraphies appear in Fig. A1. Each point represents a uniquely shaped distribution, from which on average $\sim 30$ random sedimentation rates were chosen for an uncompacted stratigraphy. The high density of the points around the line $\alpha \beta=\sim 10 \mathrm{~mm} \mathrm{yr}^{-1}$ (Fig. A1) reflects the high proportion of stratigraphies that accumulated with that ASR that compacted to within the thickness range of the stratigraphies of interest. The points between the lines $\alpha \beta=10$ and 20 represent stratigraphies with depositional thicknesses $\gg 110 \mathrm{~m}$, which ultimately compacted to between 100 and $110 \mathrm{~m}$. Our restriction that $|\mathrm{tASR}-\mathrm{aASR}|<0.1$ ASR results in very few stratigraphies with low $\alpha$ values being used $(\alpha=1$ is an exponential distribution, which we wanted to avoid). The

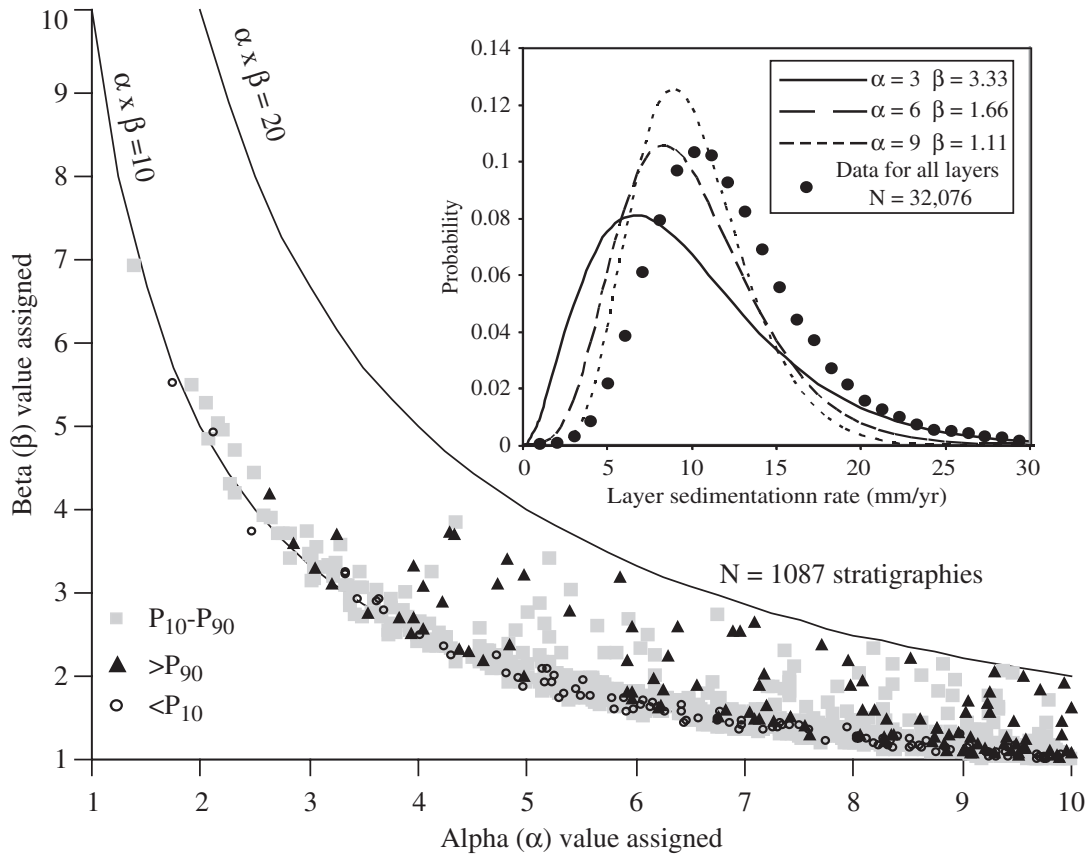

Fig. A1. $\alpha$ and $\beta$ values used to define $\Gamma$ distributions for selecting layer sedimentation rates. Each point represents a uniquely shaped $\Gamma$ distribution with an average of $\alpha \beta$. Different symbols indicated are for stratigraphies falling on different portions of the cumulative distribution function of present compaction rates (see Fig. 4). The inset histogram provides examples of three different $\Gamma$ distributions, and the distribution of all layer data (black circles). Using our method, layer sedimentation rates $>25$ or $<5 \mathrm{~mm} \mathrm{yr}^{-1}$ for any facies are rare.
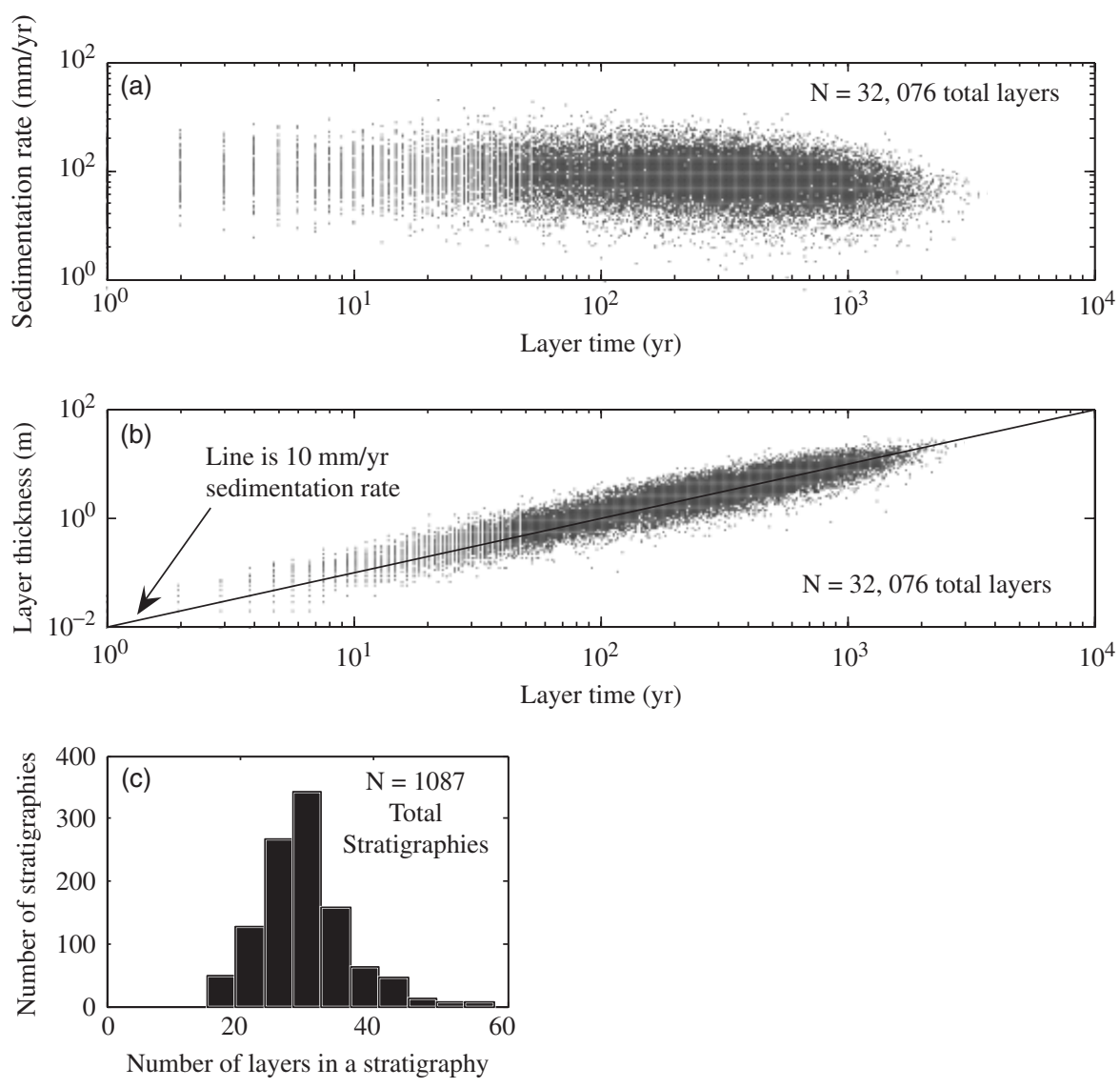

Fig. A2. Characteristics of each of the uncompacted 32076 layers used to construct the 1087 stratigraphies that compacted to a thickness between 100 and $110 \mathrm{~m}$ and had an accumulation time between 10 and $11 \mathrm{kyr}$ (a) Layer sedimentation rate vs. layer time. (b) Layer thickness vs. layer time. (c) Frequency distribution of the number of stratigraphies with a given number of layers. Thirty depositional layers are most characteristic for the stratigraphies of interest. 
inset frequency distribution (upper right of Fig. A1) provides examples of $\Gamma$ distributions for three $\alpha \beta$ pairs where $\alpha \beta=10$, and also the distribution of all 32076 layer rates assigned for all the 1087 models.

The times of accumulation for each layer are compared to that layer's sedimentation rate in Fig. A2a, and to that layer's thickness in Fig. A2b. A single point in these plots could correspond to any of the five facies used in the models. The frequency distribution of the number of layers in each of the 1087 stratigraphies is seen in Fig. A2c.

\section{REFERENCES}

Amorosi, A., Centineo, M.C., Colalongo, M.L. \& Forini, F. (2005) Millennial-scale depositional cycles from the Holocene of the Po Plain, Italy. Mar. Geo., 222-223, 7-18.

Aslan, A., Autin, W.J. \& Blum, M.D. (2005) Causes of river avulsion: insights from the late Holocene avulsion history of the Mississippi River, USA. 7. Sed. Res., 75, 650-664.

Athy, L.F. (1930) Density, porosity, and compaction of sedimentary rocks. AAPG Bull., 14(1), 1-24.

Berry, P.L. \& Poskitt, T.J. (1972) The consolidation of peat. Geotech, 22(1), 27-52.

Bloom, A.L. (1964) Peat accumulation and compaction in a Connecticut Coastal Marsh. 7. Sed. Pet., 34(3), 599-603.

Bryant, W.R., Hottman, W. \& Trabant, P. (1975) Permeability of unconsolidated and consolidated marine sediments, Gulf of Mexico. Mar. Geotech., 1(1), 1-14.

Coleman, J.M., Roberts, H.H. \& Stone, G.W. (1998) Mississippi river delta: an Overview. F. Coastal Res., 14(3), 698-716.

DACEY, M.F. (1979) Models of bed formation. Math. Geo., 11, 655-668.

DоKKA, R.K. (2006) Modern-day tectonic subsidence in coastal Louisiana. Geology, 34(4), 281-284.

FISK, H.N. (1944) Geological investigation of the alluvial valley of the lower Mississippi River, U.S. Army Corps of Engineers, Mississippi River Commission, Vicksburg, MS, 78pp.

Galloway, W.E. \& Hobday, D.K. (1996) Terrigenous Clastic Depositional Systems; Applications to Fossil Fuel and Groundwater Resources, 2nd edn. Springer, 283pp.

KooI, H. (1997) Insufficiency of compaction disequilibrium as the sole cause of high pore fluid pressures in pre-Cenozoic sediments. Bas. Res., 9(3), 227-241.

KooI, H. (2000) Land subsidence due to compaction in the coastal area of the Netherlands: role of lateral fluid flow and constraints from well-log data. Global Planet. Change, 27, 207222.

KooI, H. \& DE VRIES, J.J. (1998) Land subsidence and hydrodynamic compaction of sedimentary basins. Hydrol. Earth Syst. Sci., 2(2-3), 159-171.

Kooi, H., Johnston, P., Lambeck, K., Smither, C. \& MolenDIJK, R. (1998) Geological causes of recent $(\sim 100 \mathrm{yr})$ vertical land movement in the Netherlands. Tectonophysics, 299, 297316.

Kuecher, G.L. (1994) Geologic framework and consolidation settlement potential of the Lafourche Delta, topstratum valley fill; implications for wetland loss in Terrebonne and Lafource Parishes, Louisiana, PhD Thesis: Louisiana State University, Baton Rouge, 346pp.

Kuecher, G.J., Chandra, N., Roberts, H.H., Suhayada, J.H., Williams, S.J., Penland, S.P. \& Autin, W.J. (1993) Consolidation settlement potential in south Louisiana. In: Coastal Zone '93. Proceedings of the Eighth Symposium on Coastal and Ocean Management held in New Orleans, LA, Fuly 19-23, 1993 (Ed. by O.T. Magoon, W.S. Wilson, H. Converse \& L.T. Tobin), pp. 175192.

KuLP, M.A. (2000) Holocene stratigraphy, history, and subsidence: Mississippi River delta region, north-central Gulf of Mexico, PhDThesis, University of Kentucky, Lexington, $336 \mathrm{pp}$.

Long, A.J., Waller, M.P. \& Stupples, P. (2006) Driving mechanisms of coastal change: peat compaction and the destruction of late Holocene coastal wetlands. Mar. Geol., 225, 63-84.

Meckel, T.A., ten Brink, U. \& Williams, S.J. (2006) Current subsidence rates due to compaction of Holocene sediments in southern Louisiana. Geophys. Res. Let., 33, L11403, doi:10.1029/ 2006GL026300.

Mello, U.T., Karner, G.D. \& Anderson, R.N. (1994) A physical explanation for the positioning of the depth to the top of overpressure in shale-dominated sequences in the Gulf Coast basin, United States. 7. Geophys. Res., 99(B2), 2775-2789.

Morton, R.A., Bernier, J.C., Barras, J.A. \& Ferina, N.F. (2005) Rapid subsidence and historical wetland loss in the Mississippi delta plain: likely causes and future implications. U.S.G.S. Open-File Report 2005-1216, 116pp.

Penland, S. \& Ramsey, K.E. (1990) Relative sea-level rise in Louisiana and the Gulf of Mexico: 1908-1988. 7. Coastal Res., 6(2), 323-342.

Pizzuto, J.E. \& Schwendt, A.E. (1997) Mathematical modelling of autocompaction of a Holocene transgressive valley-fill deposit, Wolfe Glade, Delaware. Geology, 25(1), 57-60.

RAJCHL, M. \& ULIĈNÝ, D. (2005) Depositional record of an avulsive fluvial system controlled by peat compaction (Neogene, Most Basin, Czech Republic). Sedimentology, 52, 601-625.

Roberts, H.H. (1997) Dynamic changes of the Holocene Mississippi river delta plain: the delta cycle. 7. Coastal Res., 13(3), 605627.

Roberts, H.H., Bailey, A. \& Kuecher, G.J. (1994) Subsidence in the Mississippi river delta - Important influences of valley filling by cyclic deposition, primary consolidation phenomena, and early diagenesis. Trans. - Gulf Coast Assoc. Geo. Soc., 44, 619-629.

Terzaghi, K. (1943) Theoretical Soil Mechanics. J. Wiley \& Sons, New York, NY, 510pp.

Törnqvist, T.E. (1994) Middle and late Holocene avulsion history of the River Rhine (Rhine-Meuse delta, Netherlands). Geology, 22, 711-714.

Wilkinson, B.H., Merrill, G.K. \& Kivett, S.J. (2003) Stratal order in Pennsylvanian cyclothems. Geo. Soc. Am. Bull., 115(9), 1068-1087.

Manuscript received 29 May 2006; Manuscript accepted 28 November 2006 